\title{
Development and Characterization of an Active Chitosan-Based Film Containing Quercetin
}

\author{
Marthyna P. Souza ${ }^{1,2}$ • Antônio F. M. Vaz ${ }^{3}$ Hélder D. Silva ${ }^{2} \cdot$ Miguel A. Cerqueira $^{2}$ • \\ António A. Vicente ${ }^{2} \cdot$ Maria G. Carneiro-da-Cunha ${ }^{1}$
}

Received: 17 March 2015 / Accepted: 6 August 2015 / Published online: 23 August 2015

(C) Springer Science+Business Media New York 2015

\begin{abstract}
This work aims at developing an active chitosan film through the incorporation of quercetin and the evaluation of physical and functional properties of the films made thereof. The addition of quercetin showed to influence films' properties in terms of surface morphology, tensile strength, and opacity while elongation-at-break, thickness, water vapor, and oxygen permeability were not significantly affected with incorporation of quercetin. The color parameters of chitosan films were affected by quercetin incorporation with a decrease of the values of $L^{*}$ and $a^{*}$. The film exhibited a high freeradical scavenging activity, showing antioxidant activity. The film-forming solutions of chitosan with or without quercetin showed antibacterial activity against four Gram-negative and three Gram-positive bacteria. These results showed that quercetin incorporation in chitosan-based films has potential to be used as a solution for active food packaging.
\end{abstract}

Keywords Edible film · Antioxidant · Antibacterial · Polysaccharide $\cdot$ Flavonoid

Miguel A. Cerqueira

miguelcerqueira@deb.uminho.pt

Maria G. Carneiro-da-Cunha mgcc@ufpe.br

1 Biochemistry Department/Laboratory of Immunopathology Keizo Asami (LIKA), Universidade Federal de Pernambuco-UFPE, Av. Prof. Moraes Rego s/n, CEP 50.670-420 Recife, PE, Brazil

2 Centre of Biological Engineering, Universidade do Minho, Campus de Gualtar, 4710-057 Braga, Portugal

3 Unidade Acadêmica de Medicina Veterinária, Universidade Federal de Campina Grande, CEP 58.7000-970 Patos, PB, Brazil

\section{Introduction}

The use of packaging from synthetic plastics and its derivatives in food industry causes serious environmental problems (Aider 2010) giving rise to a demand of packaging alternatives from biodegradable materials. The utilization of functional compounds in order to add value to these packaging materials results in the development of active and innovative packaging systems. Some of the multifunctional functions of this packaging in food products are reduction of oxidation, inhibition of microbial growth, and control of gas mass transfer rates (Wu et al. 2013).

One of the main functions of packaging in foods is to reduce the rate of transfer of gases between the food and the environment; an adequate control of, e.g., oxygen permeability and water vapor permeability allows extending the shelf life of food products (Leceta et al. 2013).

Among all the biodegradable materials used in the development of active packaging, chitosan has received considerable attention due its unique properties (Badawy and Rabea 2011). Chitosan has been considered a biodegradable molecule, non-toxic, biocompatible, and with antimicrobial activity (Dutta et al. 2009). In addition, chitosan-based films present a structure that allows the incorporation of functional substances such as antioxidants, e.g., $\alpha$-tocopherol and tetrahydrocurcuminoids (Martins et al. 2012; Portes et al. 2009). Chitosan is a deacetylated derivative of chitin, the second most abundant polysaccharide in nature. It is a linear heteropolysaccharide consisting of units of $\mathrm{N}$-acetylglucosamine (GlcNAc) and glucosamine $(\mathrm{GlcN})$ linked by $\beta-1,4$ bonds.

The ability of chitosan-based films to incorporate active substances allows the development of functional packaging with antimicrobial and antioxidant properties, a promising system to guaranty the quality and safety of perishable food 
products. Spoilage and contamination by microorganisms and oxidation processes are responsible for the loss of quality and reduction of food safety, e.g., by triggering unpleasant tastes and odors, discoloration, and acting in the formation of harmful compounds during storage and sales ( $\mathrm{Yu}$ et al. 2013; Martins et al. 2012; Dutta et al. 2009).

Quercetin is a flavonoid presented in fruits and vegetables whose medicinal properties have been widely demonstrated in the literature, especially its antioxidant capacity. The antioxidant activity of quercetin has been attributed to its ability to scavenge free radicals generated in the aqueous phase, increasing the resistance against lipid peroxidation process (Azuma et al. 2010; Bozic et al. 2012). In the last years, several active systems have been developed using quercetin or chitosan as a functional compound; however, no studies were found showing the potential utilization of this two compounds in combination for a multifunctional (i.e., antioxidant and antimicrobial) active packaging system. During this work, quercetin was incorporated in a chitosan-based film and their physical (i.e., surface morphology, tensile strength, elongation-at-break, thickness, water vapor, and oxygen permeability and opacity) and functional properties (i.e., antioxidant and antimicrobial) where evaluated aiming the development of a new active packaging system.

\section{Material and Methods}

\section{Material}

Chitosan (degree of deacetylation $\geq 75 \%$ ) from shrimp shells and quercetin ( $>95 \%$ purity) was obtained from SigmaAldrich (St. Louis, MO, USA). Lactic acid and methanol were obtained from Merck (Darmstadt, Germany). Nurient Broth and Mueller-Hinton agar were obtained from Difco ${ }^{\mathrm{TM}}$. All other reagents were purchased from Aldrich (Steinheim, Germany).

\section{Microorganisms}

Gram-negative strains Escherichia coli (UFPEDA 224), Shigella sonnei (UFPEDA 413), Proteus mirabilis (UFPEDA 737), and Morganella morganii (UFPEDA 104) and Gram-positive strains Staphylococcus epidermidis (UFPEDA 183), Micrococcus luteus (UFPEDA 100), and Bacillus subtilis (UFPEDA 86) were provided by the Department of Antibiotics (DA), Universidade Federal de Pernambuco (UFPE), Brazil, in nutrient agar (NA) and stored at $4{ }^{\circ} \mathrm{C}$.

\section{Film Preparation}

Chitosan film forming solution was prepared dissolving $1 \%(w / v)$ chitosan in $1 \%(v / v)$ lactic acid under stirring using a magnetic stirrer (Fisatom, Brazil) at $200 \mathrm{rpm}$ for $16 \mathrm{~h}$ at room temperature $\left(25^{\circ} \mathrm{C}\right)$. The chitosan solution was then filtered to remove any undissolved particles. Quercetin-chitosan film was prepared with the addition of quercetin $\left(200 \mu \mathrm{g} \mathrm{mL}^{-1}\right)$ in the chitosan film forming solution. The quercetin-chitosan film forming solution was stirred using a magnetic stirrer at $200 \mathrm{rpm}$ for $2 \mathrm{~h}$ at $25{ }^{\circ} \mathrm{C}$ (room temperature).

Chitosan and quercetin-chitosan film forming solutions $(24 \mathrm{~mL})$ were cast in acrylic plates $(90 \mathrm{~mm} \times 15 \mathrm{~mm})$ and dried at $35 \pm 1{ }^{\circ} \mathrm{C}$ for $24 \mathrm{~h}$. Dried films were stored in desiccators at $25{ }^{\circ} \mathrm{C}$ and $54 \%$ relative humidity (obtained using a $\mathrm{Mg}\left(\mathrm{NO}_{3}\right)_{2} \cdot 6 \mathrm{H}_{2} \mathrm{O}$-saturated solution) until testing.

\section{Film Thickness}

Films thicknesses were measured with a digital micrometer (Mitutoyo, Japan), through measurements at ten random locations around each film sample and expressed as average \pm standard deviation. The average values were used in the calculation of water vapor permeability, oxygen permeability, and tensile strength.

\section{Scanning Electron Microscopy}

Film surface morphology was examined using a scanning electron microscopy (FEI, Quanta 200 FEG, USA) with an accelerating voltage from 10 to $15 \mathrm{kV}$. Before analysis, all samples were cut with a sharp scalpel and were mounted on aluminum stubs using carbon adhesive tape and sputter-coated with gold (thickness of about $12 \mathrm{~nm}$ ). The energy dispersive spectroscopy analyses were carried out in an integrated EDS-BSED (EDAX) system.

\section{Water Vapor Permeability}

The measurement of water vapor permeability (WVP) was carried out gravimetrically as described by Carneiro-da-Cunha et al. (2009). The film was sealed on the top of a permeation cell containing distilled water $\left(100 \% \mathrm{RH} ; 2337 \mathrm{~Pa}\right.$ vapor pressure at $\left.25{ }^{\circ} \mathrm{C}\right)$, placed in a desiccator at $25{ }^{\circ} \mathrm{C}$ and $0 \% \mathrm{RH}(0 \mathrm{~Pa}$ water vapor pressure) containing silica. The cells were weighted at intervals of $2 \mathrm{~h}$ during $10 \mathrm{~h}$. Steady-state and uniform water pressure conditions were assumed by keeping the air circulation constant outside the test cell using a miniature fan inside the desiccator. The slope of the weight loss versus time was obtained by linear 
regression. Three replicates were obtained for each film and the WVP was determined as follows:

$\mathrm{WVP}=\frac{\mathrm{WVTR} \times L}{\Delta P}$

where WVTR is the water vapor transmission rate $\left(\mathrm{g} \mathrm{m}^{-2} \mathrm{~s}^{-1}\right)$ through the film, $L$ is the mean film thickness $(\mathrm{m})$, and $\Delta P$ is the partial water vapor pressure difference $(\mathrm{Pa})$ across the two sides of the film. WVP expressed in grams per meter per second per pascal.

\section{Oxygen Permeability}

Oxygen permeability $\left(\mathrm{O}_{2} \mathrm{P}\right)$ was determined based on the ASTM D 3985-02 (2002) method described by Cerqueira et al. (2009). The films were sealed between two chambers, having each one two channels. In the lower chamber, the $\mathrm{O}_{2}$ was supplied at a controlled flow rate to maintain its pressure constant in that compartment. The other chamber was purged by a stream of nitrogen, also at controlled flow. Nitrogen acted as a carrier for the $\mathrm{O}_{2}$. Oxygen concentration was determined by gas chromatography (Chrompack 9001, Middleburg, Netherlands) with a column molecular sieve 5A 80/ 100 mesh $1 \mathrm{~m} \times 1 / 8^{\prime \prime} \times 2 \mathrm{~mm}$ followed by a thermal conductivity detector (TCD) at $110{ }^{\circ} \mathrm{C}$. Helium at $23 \mathrm{~mL} \mathrm{~min}^{-1}$ was used as carrier gas. Three replicates were obtained for each sample. For each replicate, three measurements were taken.

\section{Mechanical Properties}

Tensile strength (TS) and elongation-at-break (EB) were measured with an Instron Universal Testing Machine (Model 4500, Instron Corporation, USA) using film strips with a length of $45 \mathrm{~mm}$ and a width of $20 \mathrm{~mm}$. The initial grip separation was set at $30 \mathrm{~mm}$ and the crosshead speed was set at $5 \mathrm{~mm} \mathrm{~min}^{-1}$. TS was expressed in megapascal and was calculated by dividing the maximum load $(\mathrm{N})$ by the initial cross-sectional area $\left(\mathrm{m}^{2}\right)$ of the specimen. EB was calculated as the ratio of the final length at the point of sample rupture to the initial length of a specimen $(30 \mathrm{~mm})$ and expressed as a percentage. TS and EB tests were replicated three times for each sample.

\section{Color and Opacity}

The color of the films was determined with a Minolta colorimeter (CR 400; Minolta, Japan). A white color standard was used for calibration and as a background for color measurements of the films. $L^{*}, a^{*}$, and $b^{*}$ values of each film were evaluated by reflectance measurements.

The opacity $(Y)$ of the films was determined according to the Hunterlab method and calculated as the ratio between the opacity of each sample on the black standard $(\mathrm{Yb})$ and the opacity of each sample on the white standard (Yw). Three readings were made on randomly chosen reading positions for each sample. The results were expressed as a percentage as follows:

$$
Y(\%)=\frac{\mathrm{Yb}}{\mathrm{Yw}} \cdot 100
$$

\section{Determination of the Antioxidant Activity}

The antioxidant activities of chitosan and quercetin-chitosan films were measured using the 2,2-diphenyl-1- picrylhydrazyl (DPPH) radical method according to Portes et al. (2009). Htransfer between quercetin-chitosan film and DPPH in a methanol solution was monitored by UV-Vis absorption spectrometry at $515 \mathrm{~nm}$ (quartz cell length, $1 \mathrm{~cm}$; solvent, methanol). The films were cut as described above and dipped into the methanol-DPPH solution (volume, $4 \mathrm{~mL}$; DPPH concentration, $197 \mu \mathrm{mol})$ under agitation at $100 \mathrm{rpm}$. The experiments were repeated five times. By monitoring the decay of DPPH absorption $\left(\lambda_{\max }=515 \mathrm{~nm}, \varepsilon=11,240 \mathrm{~L} \mathrm{~mol}^{-1} \mathrm{~cm}^{-1}\right)$ after reaction with quercetin contained in the chitosan film with the DPPH in solution, mathematical models describing the kinetics of reaction/release of functional compound in the film were adjusted to the experimental data. The mathematical models used were zeroth order, first order, second order, and the Higuchi model. The regression analyses were carried out using the following four models (Eqs. 3-6):

1. $\quad[\mathrm{DPPH}]$ versus $t$ (zeroth order)

$$
[\mathrm{DPPH}]_{t}=k_{0} \cdot t
$$

2. $\ln [\mathrm{DPPH}]$ versus $t$ (first order)

$$
\ln [\mathrm{DPPH}]_{t}=\ln [\mathrm{DPPH}]_{0}-k_{1} \cdot t
$$

3. $\quad 1 /[\mathrm{DPPH}]$ versus $t$ (second order)

$$
\frac{1}{[D P P H]_{t}}=\frac{1}{[D P P H]_{0}}+k_{2} \cdot t
$$

4. [DPPH] versus square root of $t$ (Higuchi model).

$$
[\mathrm{DPPH}]_{t}=k_{H} \cdot t^{1 / 2}
$$

where [DPPH] is the fraction of DPPH consumption at time $t$ and 0 and the constants $k_{0}, k_{1}, K_{2}$, and $k_{H}$ represent, respectively the reaction/release constant of zero order, first order, second order, and Higuchi. The values of $k_{0}, k_{1}, K_{2}$, and $k_{H}$ were determined by fitting each of the Eqs. $3-6$ to DPPH consumption versus time data. 


\section{Antibacterial Activity—Agar-Well Diffusion Method}

Gram-negative and Gram-positive bacteria strains were grown in shaker flasks $(250 \mathrm{~mL})$ containing Nutrient Broth and incubated overnight in an orbital shaker at $100 \mathrm{rpm}$ and $37^{\circ} \mathrm{C}$. Biomass concentration was determined measuring the suspension turbidity at $600 \mathrm{~nm}$ and then converted to colony-forming

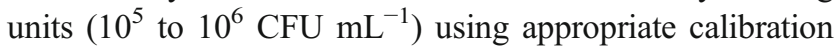
curves (turbidity equivalent to 0.5 in the McFarland scale). One CFU represents a viable cell capable of promoting bacterial growth.

Antibacterial effect of quercetin, chitosan, and quercetinchitosan film forming solutions was determined using agarwell diffusion methods. Suspensions of tested microorganisms were spread onto the surface of Mueller-Hinton agar plates. Wells of $6 \mathrm{~mm}$ diameter were cut from the agar and filled with $20 \mu \mathrm{L}$ of quercetin-DMSO solution $\left(200 \mu \mathrm{L} \mathrm{mL}{ }^{-1}\right)$, chitosan, and quercetin-chitosan filmogenic solutions. The solvent control was carried out using DMSO and $1 \%(v / v)$ lactic acid solution. The inoculated plates were incubated at $37^{\circ} \mathrm{C}$ for $24 \mathrm{~h}$. Antibacterial activity was evaluated measuring the diameter of the growth inhibition zone around the well. All tests were carried out in triplicate.

\section{Statistical Analyses}

The statistical analyses for antibacterial activity were carried out using analysis of variance (ANOVA). Comparisons between samples were analyzed using Student's $t$ test or Tukey's test. Statistical significance was established at $p<0.05$ (GraphPad Prism, version 6, 2012, USA).

\section{Results and Discussion}

\section{Scanning Electron Microscopy}

Figure 1 shows scanning electron micrographs of chitosan and chitosan-quercetin films. The surface of chitosan film (Fig. 1a) appears to be smooth and uniform, suggesting the formation of an ordered matrix. A previous study has shown the surface of chitosan films to be smooth, uniform, and compact (Pinotti et al. 2007). The chitosan-quercetin film (Fig. 1b) appears with a fibrous surface with nodular needle shape, which can be explained by the formation of quercetin crystals, which tend to aggregate into a closely packed arrangement (Srinivas et al. 2010). Quercetin displays an amphipathic behavior due to the phenyl rings that form the hydrophobic part of the molecule and the hydroxyl groups constituting the polar portion. However, quercetin solubility in water is poor, which can explain the formation of quercetin crystals and their presence in the surface (Srinivas et al. 2010; Patel et al. 2012). The results are in agreement with Norajit et al. (2010) that showed the effect of the incorporation of red ginseng extract on alginate-based film, where the surface smoothness of alginate film was changed with the appearance of a fibrous surface.

\section{Water Vapor Permeability}

The water vapor permeability is an important parameter since it determines the ability of the films to interact with water and to promote protection against dehydration process or re-hydration of the food, such in fresh and dried fruits, respectively. Chitosan and quercetin-chitosan films presented WVP values of $23.28 \pm 2.84$ and $24.00 \pm 3.14 \times 10^{-11} \mathrm{~g} \mathrm{~m} \mathrm{~m}^{-2} \mathrm{~s}^{-1} \mathrm{~Pa}^{-1}$, respectively, with no significant difference ( $p>0.05)$, which confirms that the addition of quercetin did not lead to any change in this parameter. WVP values obtained for the quercetin-chitosan films are in agreement with those reported for other polysaccharide-based films. Martins et al. (2012) obtained WVP values of $6.02 \pm 0.40 \times 10^{-11} \mathrm{~g} \mathrm{~m} \mathrm{~m}^{-2} \mathrm{~s}^{-1} \mathrm{~Pa}^{-1}$ for chitosan films $(1.5 \% w / v)$ with Tween $80(0.1 \% w / v)$. In other work, films were produced using a polysaccharide from Anacardium occidentale L. tree $(1.5 \% \mathrm{w} / \mathrm{v})$ with sorbitol $(0.4 \% w / w)$ and Tween $80(0.1 \% w / v)$ and presented WVP values of $10.83 \pm 0.22 \times 10^{-11} \mathrm{~g} \mathrm{~m} \mathrm{~m}^{-2} \mathrm{~s}^{-1} \mathrm{~Pa}^{-1}$ (Carneiro-daCunha et al. 2009). These values are in the range of permeability values for galactomannan-based films used on fruits (apple and mango) and cheese, which were found to be suitable to increase the storage time of those products (Lima et al. 2010; and Martins et al. 2010).

A great number of factors can affect the WVP of chitosan films as, e.g., film thickness and crystallinity. Generally, the WVP depends on the diffusivity and solubility of water molecules in the film matrix (Wang et al. 2013). In this case, the incorporation of quercetin does not influence thickness $(p>0.05)$ of chitosan-based film, presenting thickness values of $5.43 \pm 0.83 \mathrm{~mm}$ (chitosan film) and $5.49 \pm 0.43 \mathrm{~mm}$ (quercetin-chitosan film). For instance, Martins et al. (2012) showed that the incorporation of $0.1 \%$ of $\alpha$-tocopherol in chitosan films does not change WVP values but increases their thickness. However, the incorporation of $0.2 \%$ of $\alpha$ tocopherol led to an increase of WVP while maintaining thickness values.

Obtained results suggest that the presence of quercetin in chitosan films did not reduce the availability of hydrophilic groups of chitosan, maintaining their interactions with water molecules that can be due to the low concentration $(0.02 \%)$ of quercetin used in this work that does not change the original hydrophilic-hydrophobic equilibrium of chitosan films.

\section{Oxygen Permeability}

Oxidation reactions are responsible for changes in color, odor, and taste of food. Therefore, films which provide an adequate 
Fig. 1 Scanning electron microscopy micrographs of films surface. a Chitosan film. b Quercetin-chitosan film
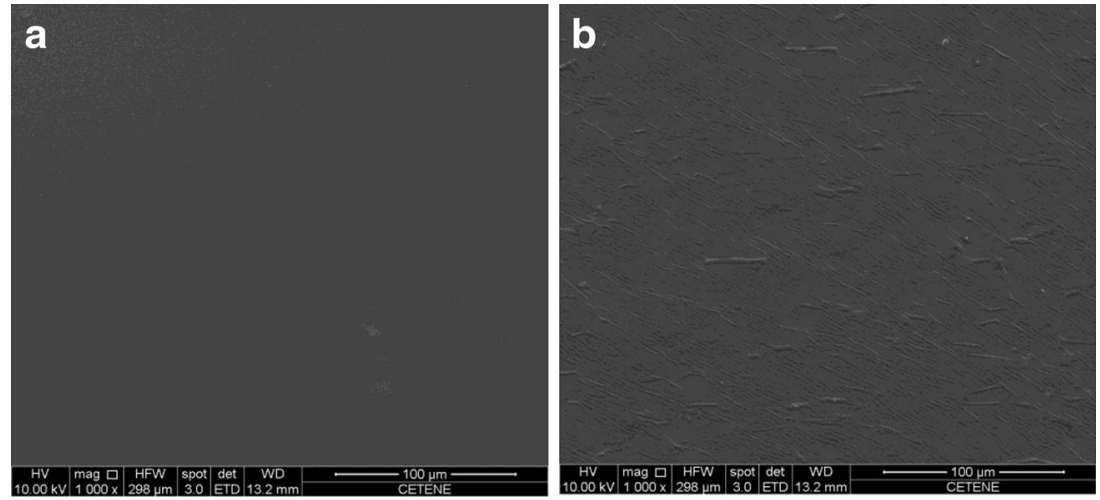

barrier to oxygen can help improving quality of foods (e.g., fruits and cheese) and prolonging their shelf life (Cerqueira et al. 2010; Lima et al. 2010).

$\mathrm{O}_{2} \mathrm{P}$ values of chitosan and quercetin-chitosan films were found to be $7.47 \pm 0.50 \times 10^{-13}$ and $6.20 \pm 0.85 \times$ $10^{-13} \mathrm{~g} \mathrm{~m}^{-1} \mathrm{~Pa}^{-1} \mathrm{~s}^{-1}$, respectively, without statistically significant difference $(p>0.05)$. These results are in agreement and in the same order of magnitude of the values found by Rubilar et al. (2013) for chitosan films $\left(5.33 \times 10^{-13} \mathrm{~g} \mathrm{~m}^{-1} \mathrm{~Pa}^{-1} \mathrm{~s}^{-1}\right)$ and for chitosan films with $3.2 \%$ of carvacrol plus $34.2 \%$ of grape seed extract $\left(6.20 \times 10^{-13} \mathrm{~g} \mathrm{~m}^{-1} \mathrm{~Pa}^{-1} \mathrm{~s}^{-1}\right)$. The permeability of a film depends on its chemical structure, morphology, and the nature of permeant (Siripatrawan and Harte 2010). Figure 1 shows that the incorporation of quercetin led to changes in the matrix microstructure of chitosan, which were not enough to change the oxygen permeability of the films.

\section{Mechanical Properties}

The desired mechanical properties of an edible film depend on its application and on the subsequent transport and handling of foods. Mechanical strength is generally required to maintain the structural integrity and barrier properties of edible films. However, appropriate deformability is also desired for easy handling in most applications (Chen and Lai 2008).

Results showed that the incorporation of quercetin into chitosan films significantly affected $(p<0.05)$ TS values but did not significantly change $(p>0.05)$ the values of EB (Table 1). The decrease of TS values can be explained by the change of intramolecular bonding with the addition of quercetin. The addition of a hydrophobic agent to quitosanbased films induces the development of structural discontinuities, producing a film structure with less chain mobility and, consequently, with less resistance to fracture (Rubilar et al. 2013). Other authors also described differences between TS and EB values when compounds are added to chitosan films; in fact, Rubilar et al. (2013) and Moradi et al. (2012) showed that the incorporation of antioxidant extracts and essential oils into chitosan-based films decreased both TS and EB.
Siripatrawan and Harte (2010) showed that the incorporation of green tea extract (GTE) into chitosan films did not significantly change TS and EB when GTE concentration increased from 0 to $5 \%$, but significantly increased when GTE concentration increased from 5 to $20 \%$. This behavior was attributed to the interaction between chitosan matrix and polyphenolic compounds of GTE.

\section{Color and Opacity}

Optical properties are essential to define the ability of films to be applied on a food surface, since these can affect the appearance of the coated product (Pereda et al. 2012). Table 2 shows the results of color and opacity for chitosan and quercetinchitosan films. The color of chitosan films was affected by quercetin incorporation decreasing the values of $L^{*}$ and $a^{*}$. Lower values of $L^{*}$ indicate less luminosity, brightness and transparency and, consequently, a darker film. Chitosan films were slightly yellow and transparent. Their transparency was reduced with quercetin incorporation and the negative values of $a^{*}$ demonstrate that they tend to green color. These results are in agreement with those reporting the addition of $\alpha$ tocoferol (Martins et al. 2012) and green tea extract (Siripatrawan and Harte 2010) into chitosan films that also led to a decrease of films transparency.

Table 1 Values of oxygen permeability $\left(\mathrm{O}_{2} \mathrm{P}\right)$, water vapor permeability (WVP), opacity, tensile strength (TS), and elongation-at-break (EB) end thickness obtained for chitosan and quercetin-chitosan films

\begin{tabular}{lrc}
\hline Properties & Chitosan film & Quercetin-chitosan films \\
\hline $\mathrm{O}_{2} \mathrm{P} \times 10^{-13}{\mathrm{~g} \mathrm{~m}\left(\mathrm{~Pa} \mathrm{~s} \mathrm{~m}^{2}\right)^{-1}}^{2}$ & $7.47 \pm 0.50^{\mathrm{a}}$ & $6.20 \pm 0.85^{\mathrm{a}}$ \\
$\mathrm{WVP} \times 10^{-11}{\mathrm{~g} \mathrm{~m}\left(\mathrm{~Pa} \mathrm{~s} \mathrm{~m}^{2}\right)^{-1}}^{23.38 \pm 2.84^{\mathrm{a}}}$ & $24.00 \pm 3.14^{\mathrm{a}}$ \\
$\mathrm{TS}(\mathrm{MPa})$ & $6.67 \pm 0.34^{\mathrm{a}}$ & $5.48 \pm 0.58^{\mathrm{b}}$ \\
$\mathrm{EB}(\%)$ & $35.16 \pm 7.02^{\mathrm{a}}$ & $39.54 \pm 7.79^{\mathrm{a}}$ \\
Thickness $\left(10^{-5} \mathrm{~m}\right)$ & $5.43 \pm 0.83^{\mathrm{a}}$ & $5.49 \pm 0.43^{\mathrm{a}}$ \\
\hline
\end{tabular}

Equal superscript letters in the same line indicate the absence of statistically significant differences $(p>0.05)$ 
Table 2 Color and opacity values of the chitosan and quercetinchitosan films

\begin{tabular}{|c|c|c|c|c|}
\hline Film & $L^{*}$ & $a^{*}$ & $b^{*}$ & Opacity (\%) \\
\hline Chitosan & $96.43 \pm 0.33^{\mathrm{a}}$ & $4.54 \pm 0.03^{\mathrm{a}}$ & $1.12 \pm 0.35^{\mathrm{a}}$ & $9.90 \pm 0.48^{\mathrm{a}}$ \\
\hline $\begin{array}{l}\text { Quercetin- } \\
\text { chitosan }\end{array}$ & $94.47 \pm 0.37^{\mathrm{b}}$ & $-3.77 \pm 0.23^{b}$ & $28.78 \pm 2.39^{b}$ & $18.72 \pm 0.75^{b}$ \\
\hline
\end{tabular}

Equal superscript letters in the same column indicate the absence of statistically significant differences $(p>0.05)$

The opacity of the chitosan film increased about $89 \%$ with the incorporation of quercetin. This increase may make of the quercetin-chitosan film a barrier to prevent light-induced oxidative deterioration when applied in food products, avoiding nutrient losses, discoloration, and off-flavors. Increases of opacity of about 117.7 and $290 \%$ were found in chitosan films with the addition of green tea extract in concentrations of 2.0 and $20.0 \%(w / v)$, respectively (Siripatrawan and Harte 2010).

\section{Antioxidant Activity of Quercetin-Chitosan Film}

The oxidation process of food products during production and storage causes a sequence of particularly unfavorable changes in the sensory properties of the product (e.g., appearance of rancidity, changes in color and texture) responsible for the quality decay and economic losses (Gramza and Korczak 2005). Incorporation of antioxidants into food packaging materials to control the oxidation of fatty components and pigments can contribute to preserve the quality of food products (Portes et al. 2009).

In this work, as expected, no antioxidant activity was observed for chitosan-based film, confirming the results obtained by Portes et al. (2009) with chitosan films at $2 \%(w / v)$. Ruiz-Navajas et al. (2013) showed that chitosan films exhibit a mild antioxidant activity, which is related to the fact that free radicals can react with the residual-free amino groups $\left(-\mathrm{NH}_{2}\right)$ of chitosan forming ammonium groups $\left(-\mathrm{NH}_{3}{ }^{+}\right)$through absorption of a hydrogen ion from the solution.

Figure 2 shows the consumption of DPPH by quercetinchitosan film versus time. The ability of phenolic groups of quercetin to donate hydrogen to stabilize free radicals was retained after the incorporation in chitosan films. Among the flavonoids, quercetin is one of the most effective antioxidants due to the $o$-hydroxy structure in the B ring, the 2, 3 double bond in conjugation with the 4-oxo function in the $\mathrm{C}$-ring and the 3- and 5-OH groups with the 4-oxo function in the $\mathrm{A}$ and $\mathrm{C}$ rings (Fahlman and Krol 2009).

The order of reaction of [ $\left.\mathrm{DPPH}^{\bullet}\right]$ and antioxidant $[\mathrm{AH}]$ is depended on the relative concentration of reactants (Mishra et al. 2012). Scavenging reaction between [ $\left.\mathrm{DPPH}^{\bullet}\right]$ and $[\mathrm{AH}]$ is represented by Eq. (7), being $[\mathrm{AH}]$ the concentration of quercetin. The less-reactive species $\left[\mathrm{A}^{\bullet}\right]$ (which represents
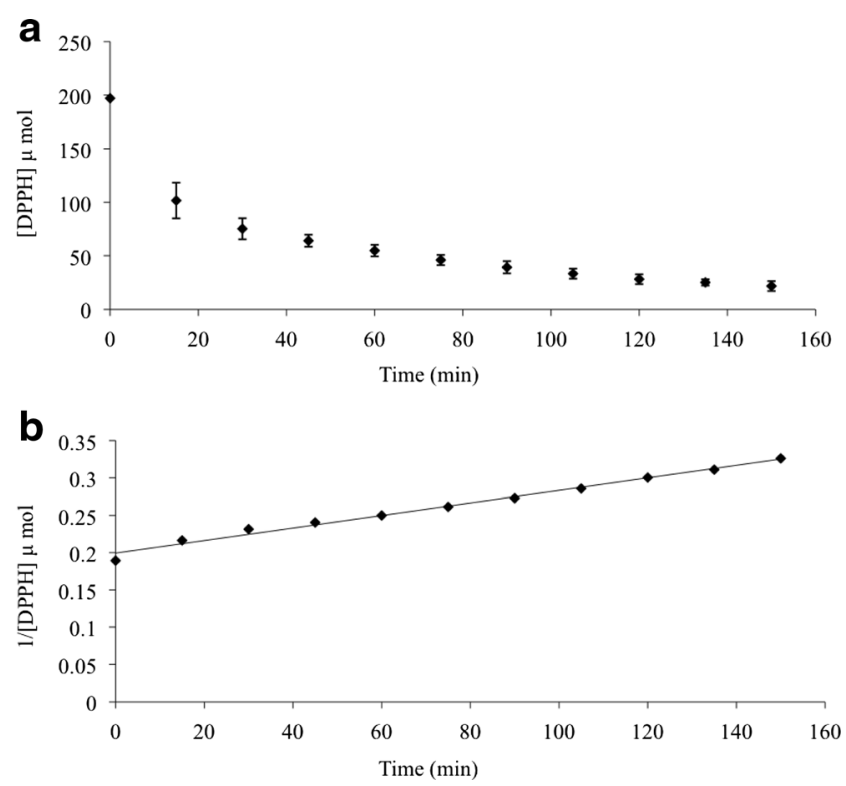

Fig. 2 a DPPH consumed by quercetin-chitosan film versus time. Each data point is an average of five determinations and the error bars show the standard deviation. b 1/DPPH consumed by quercetin-chitosan film versus time. The black line represents the fitting of the experimental data to the second-order model

oxidized quercetin) can undergo interactions with another $\left[\mathrm{DPPH}^{\bullet}\right]$ according to Eq. (8). However, this secondary reaction may be of limited occurrence.

$\left[\mathrm{DPPH}^{*}\right]+[\mathrm{AH}] \leftrightarrow \mathrm{DPPH}_{2}+\left[\mathrm{A}^{*}\right]$

$\left[\mathrm{DPPH}^{*}\right]+\left[\mathrm{A}^{*}\right] \leftrightarrow \mathrm{DPPH}-\mathrm{A}$

The reaction kinetic constants of DPPH consumption determined from the mathematical models are presented in Table 3. The regression coefficients for the different kinetic models show that the second-order reaction model was the one that best fitted with the decrease of DPPH concentration. The reaction kinetics are in agreement with the results obtained for other antioxidants such as butyrated hydroxyl toluene (BHT) and curcumin and, furthermore, second-order parameters $\left(K_{2(0-30 \mathrm{~min})}=2 \times 10^{-5} \mu \mathrm{M}^{-1} \mathrm{~s}^{-1}\right)$ are close to those reported by Mishra et al. (2012) for curcumin, ascorbic acid, and sesamol $\left(2.25,2,1.3 \times 10^{-5} \mu \mathrm{M}^{-1} \mathrm{~s}^{-1}\right.$, respectively), showing

Table 3 Kinetics parameters of DPPH consumption fitted to four mathematical models

\begin{tabular}{llll}
\hline Zero order & First order & Second order & Higuchi \\
\hline$K_{0}=0.8504$ & $K_{1}=0.0129$ & $K_{2}=0.0008$ & $k_{H}=-13.13$ \\
- & {$[D P P H]_{0}=0.21$} & {$[D P P H]_{0}=5.02$} & - \\
$R^{2}=0.69329$ & $R^{2}=0.94093$ & $R^{2}=0.98899$ & $R^{2}=0.91206$ \\
\hline
\end{tabular}


Table 4 Antibacterial activity of quercetin, chitosan, quercetinchitosan film-forming solutions and solvents by Agar-well diffusion method

\begin{tabular}{|c|c|c|c|c|c|}
\hline \multirow[t]{3}{*}{ Microorganisms } & \multicolumn{5}{|c|}{ Inhibition zone in diameter $(\mathrm{mm})$} \\
\hline & \multicolumn{3}{|c|}{ Film-forming solutions } & \multicolumn{2}{|l|}{ Control } \\
\hline & Quercetin & Chitosan & Quercetin-chitosan & Lactic acid & DMSO \\
\hline E. coli & NI & $25.3 \pm 1.5^{\mathrm{a}}$ & $29.3 \pm 1.1^{\mathrm{a}}$ & $16.6 \pm 3.2^{\mathrm{b}}$ & NI \\
\hline S. sonnei & NI & $22.3 \pm 0.5^{\mathrm{b}}$ & $25.0 \pm 0.0^{\mathrm{a}}$ & $17.6 \pm 1.1^{\mathrm{c}}$ & NI \\
\hline P. mirabilis & NI & $22.6 \pm 1.1^{\mathrm{b}}$ & $27.0 \pm 1.0^{\mathrm{a}}$ & $16.6 \pm 1.5^{\mathrm{c}}$ & NI \\
\hline M. morganii & NI & $24.3 \pm 0.5^{\mathrm{b}}$ & $27.6 \pm 0.5^{\mathrm{a}}$ & $17.6 \pm 0.5^{\mathrm{c}}$ & NI \\
\hline S. epidermidis & NI & $21.0 \pm 1.0^{\mathrm{b}}$ & $24.3 \pm 2.0^{\mathrm{a}}$ & $17.6 \pm 0.5^{\mathrm{c}}$ & NI \\
\hline M. luteus & NI & $24.3 \pm 1.1^{\mathrm{a}}$ & $24.0 \pm 1.0^{\mathrm{a}}$ & $14.3 \pm 2.0^{\mathrm{b}}$ & NI \\
\hline B. subtilis & $\mathrm{NI}$ & $24.0 \pm 4.3^{\mathrm{a}}$ & $26.0 \pm 3.4^{\mathrm{a}}$ & $11.3 \pm 4.0^{\mathrm{b}}$ & NI \\
\hline
\end{tabular}

Equal superscript letters in the same line indicate the absence of statistically significant differences $(p>0.05)$. Each data is an average of three determinations \pm standard deviation.

NI no inhibition the potential use of chitosan-based films to act as a carrier for quercetin, maintaining the same antioxidant behavior than free compounds. Mishra et al. (2012) presented the second-order reaction constant $\left(K_{2}\right)$ at 30 min for other antioxidant compounds being the $K_{2}$ values for gallic acid, alpha-tocopherol, BHT, and ferulic acid are 4.0, 0.85, 0.3, and 0.55 $10^{-5} \mu \mathrm{M}^{-1} \mathrm{~s}^{-1}$, respectively. Results are also in agreement with the results obtained for chitosan films with the incorporation of tea polyphenols, which presented a similar antioxidant activity (Siripatrawan and Harte 2010).

\section{Antibacterial Activity}

Table 4 shows the values of antibacterial activity of filmforming solutions of quercetin, chitosan, quercetin-chitosan, and their respective controls (DMSO and lactic acid) against Gram-positive and Gram-negative bacteria. Results show that the solution containing only quercetin $\left(200 \mu \mathrm{g} \mathrm{mL}^{-1}\right)$ was not effective against bacterial growth. In other study, Gatto et al. (2002) assess the antibacterial effect of quercetin against Gram-positive bacteria (Staphylococcus aureus, B. subtilis, Listeria ivanovi, Listeria monocytogenes, Listeria serligeri) and Gram-negative bacteria (E. coli, Shigella flexneri, S. sonnei, Salmonella enteritidis, Salmonella tiphymurium) and found that up to a concentration of $100 \mu \mathrm{g} \mathrm{mL}^{-1}$ quercetin does not display antimicrobial activity. However, other studies report that quercetin has antibacterial activity and that the activity is related to a number of factors including the inhibition of nucleic acid synthesis (inhibition of DNA gyrase), permeability increase of bacterial internal membrane, and dissipation of membrane potential. The electrochemical proton gradient across the membrane is essential for the bacterium to maintain the ability to synthesize ATP, as well as the functions of membrane transport and motility (Cushnie and Lamb 2005; Bozic et al. 2012). Apparently, quercetin affects such gradient thus affecting cell viability.
The film-forming solutions of chitosan showed antibacterial activity against all tested Gram-positive and Gramnegative bacteria with inhibition zones ranging from 21.00 to $25.33 \mathrm{~mm}$. The most widespread hypothesis for the antibacterial activity of chitosan is the change in cell permeability due to the interactions between the positively charged chitosan molecules at acidic $\mathrm{pH}$ and the surface of bacterial cells that have a residual negative charge. This interaction leads to leakage of electrolytes and intracellular protein constituents (Mohamed et al. 2013; Pereda et al. 2011; Devlieghere et al. 2004). The antibacterial activity of the chitosan film forming solutions was not compromised by the addition of quercetin. In the strains of S. sonnei, P. mirabilis, M. morganii, and $S$. epidermidis, the film-forming solution containing quercetin-chitosan present higher inhibition zones in comparison with the solution containing only chitosan, suggesting also an antibacterial activity of quercetin at low concentrations when added in film-forming solutions. A similar effect was observed by Guirguis et al. (2013) with the incorporation of Jojoba liquid wax on chitosan films. They found an increased microbial activity against $S$. aureus and $B$. subtilis.

These findings suggest that quercetin-chitosan film can be used as natural antibacterial agent, preventing the growth of food-borne bacteria and limiting the contamination by pathogenic bacteria, thereby contributing to prolonging the shelf life and improvement of safety of the food product.

\section{Conclusion}

The present work shows that quercetin can be successfully added to chitosan-based films, while keeping chitosan-based films' good mechanical and barrier properties. The quercetinchitosan films obtained were more opaque than chitosanbased films and of greenish color. Moreover, results showed that quercetin-chitosan films may be used as active packaging 
for food products as they showed antibacterial and antioxidant activity in vitro. It is therefore suggested that chitosan-quercetin films and coatings may be used as active packaging materials, contributing to food preservation and shelf-life extension.

Acknowledgments Author Marthyna Pessoa de Souza thanks the Coordenação de Aperfeiçoamento de Pessoal de Nivel Superior (CAPES/PDEE-Brazil) and Fundação de Amparo à Ciência e Tecnologia do Estado de Pernambuco (FACEPE, Brazil) for fellowships. Miguel A. Cerqueira and Hélder D. Silva (SFRH/BPD/72753/2010 and SFRH/BD/ $81288 / 2011$, respectively) are recipients of a fellowship from the Fundação para a Ciência e Tecnologia (FCT, POPH-QREN and FSE Portugal). This research was financially supported by research grants and fellowships from the Conselho Nacional de Desenvolvimento Científico e Tecnológico (CNPq), as well as the Coordenação de Aperfeiçoamento de Pessoal de Nível Superior (CAPES) and Fundação de Amparo à Ciência e Tecnologia do Estado de Pernambuco (FACEPE). The authors also thank the FCT Strategic Project of UID/BIO/04469/ 2013 unit, the project RECI/BBB-EBI/0179/2012 (FCOMP-01-0124FEDER-027462), and the project "BioInd - Biotechnology and Bioengineering for improved Industrial and Agro-Food processes," REF. NORTE-07-0124-FEDER-000028 Co-funded by the Programa Operacional Regional do Norte (ON.2-O Novo Norte), QREN, FEDER

\section{References}

Aider, M. (2010). Chitosan application for active bio-based films production and potential in the food industry: review. $L W T$ - Food Science and Technology, 43, 837-842.

ASTM D 3985-02. (2002). Standard test method for oxygen gas transmission rate through plastic film and sheeting using a coulometric sensor. In Annual book of ASTM. Philadelphia, PA: Amer. Soc. for Testing \& Materials.

Azuma, K., Ippoushi, K., \& Terao, J. (2010). Evaluation of tolerable levels of dietary quercetin for exerting its antioxidative effect in high cholesterol-fed rats. Food and Chemical Toxicology, 48, 1117-1122.

Badawy, M.E.I., \& Rabea, E.I. (2011). A biopolymer chitosan and its derivatives as promising antimicrobial agents against plant pathogens and their applications in crop protection. International Journal of Carbohydrate Chemistry, 29p.

Bozic, M., Gorgieva, S., \& Kokol, V. (2012). Homogeneous and heterogeneous methods for laccase-mediated functionalization of chitosan by tannic acid and quercetin. Carbohydrate Polymers, 89, 854-864.

Carneiro-da-Cunha, M. G., Cerqueira, M. A., Souza, B. W. S., Souza, M. P., Teixeira, J. A., \& Vicente, A. A. (2009). Physical properties of edible coatings and films made with a polysaccharide from Anacardium occidentale L. Journal of Food Engineering, 95, 379-385.

Cerqueira, M. A., Lima, A. M., Teixeira, J. A., Moreira, R. A., \& Vicente, A. A. (2009). Suitability of novel galactomannans as edible coatings for tropical fruits. Journal of Food Engineering, 94, 372-378.

Cerqueira, M. A., Sousa-Gallagher, M. J., Macedo, I., RodriguezAguilera, R., Souza, B. W. S., Teixeira, J. A., \& Vicente, A. A. (2010). Use of galactomannan edible coating application and storage temperature for prolonging shelf-life of "regional" cheese. Journal of Food Engineering, 97(1), 87-94.

Chen, C. H., \& Lai, L. S. (2008). Mechanical and water vapor barrier properties of tapioca starch/decolorized hsian-tsao leaf gum films in the presence of plasticizer. Food Hydrocolloids, 22, 1584-1595.

Cushnie, T. P. T., \& Lamb, A. J. (2005). Antimicrobial activity of flavonoids. International Journal of Antimicrobial Agents, 26, 343-356.
Devlieghere, F., Vermeulen, A., \& Debevere, J. (2004). Chitosan: antimicrobial activity, interactions with food components and applicability as a coating on fruit and vegetables. Food Microbiology, 21, 703-714.

Dutta, P. K., Tripathi, S., Mehrotra, G. K., \& Dutta, J. (2009). Perspectives for chitosan based antimicrobial films in food applications. Food Chemistry, 114, 1173-1182.

Fahlman, B. M., \& Krol, E. S. (2009). UVA and UVB radiation-induced oxidation products of quercetin. Journal of Photochemistry and Photobiology B: Biology, 97, 123-131.

Gatto, M. T., Falcocchio, S., Grippa, E., Mazzanti, G., Battinelli, L., Nicolasi, G., Lambusta, D., \& Saso, L. (2002). Antimicrobial and antilipase activity of quercetin and its C2-C16 3-O-acyl-esters. Bioorganic \& Medicinal Chemistry, 10, 269-272.

Gramza, A., \& Korczak, J. (2005). Tea constituents (Camellia sinensis L.) as antioxidants in lipid systems. Trends in Food Science \& Technology, 16, 351-358.

Guirguis, O. W., Elkader, M. F. H. A., \& Nasrat, A. A. (2013). Enhancing antimicrobial activity for chitosan by adding Jojoba liquid wax. Materials Letters, 93, 353-355.

Leceta, I., Guerrero, P., \& Caba, K. (2013). Functional properties of chitosan-based films. Carbohydrate Polymers, 93, 339-346.

Lima, A. M., Cerqueira, M. A., Souza, B. W. S., Santos, E. C. M., Teixeira, J. A., Moreira, R. A., \& Vicente, A. A. (2010). New edible coatings composed of galactomannans and collagen blends to improve the postharvest quality of fruits - influence on fruits gas transfer rate. Journal of Food Engineering, 97(1), 101-109.

Martins J. T., Cerqueira M. A., Souza B. W. S., Avides M. C., \& Vicente A. A. (2010). Shelf-life extension of Ricotta cheese using coatings of galactomannans from non-conventional sources incorporating nisin against Listeria monocytogenes. Journal of Agricultural and Food Chemistry, 58, 1884-1891.

Martins, J. T., Cerqueira, M. A., \& Vicente, A. A. (2012). Influence of $\alpha$ tocopherol on physicochemical properties of chitosan-based films. Food Hydrocolloids, 27, 220-227.

Mishra, K., Ojha, H., \& Chaudhury, N. K. (2012). Estimation of antiradical properties of antioxidants using DPPH assay: a critical review and results. Food Chemistry, 130, 1036-1043.

Mohamed, C., Clementine, K. A., Didier, M., Gérard, L., \& Noëlle, D. C. M. (2013). Antimicrobial and physical properties of edible chitosan films enhanced by lactoperoxidase system. Food Hydrocolloids, 30, $576-580$.

Moradi, M., Tajik, H., Rohani, S. M. R., Oromiehie, A. R., Malekinejad, H., Aliakbarlu, J., \& Hadian, M. (2012). Characterization of antioxidant chitosan film incorporated with Zataria multiflora Boiss essential oil and grape seed extract. LWT - Food Science and Technology, $46,477-484$.

Norajit, K., Kim, K. M., \& Ryu, G. H. (2010). Comparative studies on the characterization and antioxidant properties of biodegradable alginate films containing ginseng extract. Journal of Food Engineering, 98, 377-384.

Patel, A. R., Heussen, P. C. M., Hazekamp, J., Drost, E., \& Velikov, K. P. (2012). Quercetin loaded biopolymeric colloidal particles prepared by simultaneous precipitation of quercetin with hydrophobic protein in aqueous medium. Food Chemistry, 133, 423-429.

Pereda, M., Ponce, A. G., Marcovich, N. E., Ruseckaite, R. A., \& Martucci, J. F. (2011). Chitosan-gelatin composites and bi-layer films with potential antimicrobial activity. Food Hydrocolloids, 25, 1372-1381.

Pereda, M., Amica, G., \& Marcovich, N. E. (2012). Development and characterization of edible chitosan/olive oil emulsion films. Carbohydrate Polymers, 87, 1318-1325.

Pinotti, A., Garcia, M. A., Martino, M. N., \& Zaritzky, N. E. (2007). Study on microstructure and physical properties of composite films based on chitosan and methylcellulose. Food Hydrocolloids, 21(1), 66-72. 
Portes, E., Gardrat, C., Castellan, A., \& Coma, V. (2009). Environmentally friendly films based on chitosan and tetrahydrocurcuminoid derivatives exhibiting antibacterial and antioxidative properties. Carbohydrate Polymers, 76, 578-584.

Rubilar, J. F., Cruz, R. M. S., Silva, H. D., Vicente, A. A., Khmelinskii, I., \& Vieira, M. C. (2013). Physico-mechanical properties of chitosan films with carvacrol and grape seed extract. Journal of Food Engineering, 115, 466-474.

Ruiz-Navajas, Y., Viuda-Martos, M., Sendra, E., Perez-Alvarez, J. A., \& Fernández-López, J. (2013). In vitro antibacterial and antioxidant properties of chitosan edible films incorporated with Thymus moroderi or Thymus piperella essential oils. Food Control, 30, 386-392.

Siripatrawan, U., \& Harte, B. R. (2010). Physical properties and antioxidant activity of an active film from chitosan incorporated with green tea extract. Food Hydrocolloids, 24, 770-775.
Srinivas, K., King, J. W., Howard, L. R., \& Monrad, J. K. (2010). Solubility and solution thermodynamic properties of quercetin and quercetin dihydrate in subcritical water. Journal of Food Engineering, 100, 208-218.

Wang, L., Dong, Y., Men, H., Tong, J., \& Zhou, J. (2013). Preparation and characterization of active films based on chitosan incorporated tea polyphenols. Food Hydrocolloids, 32, 35-41.

Wu, J., Chen, S., Ge, S., Miao, J., Li, J., \& Zhang, Q. (2013). Preparation, properties and antioxidant activity of an active film from silver carp (Hypophthalmichthys molitrix) skin gelatin incorporated with green tea extract. Food Hydrocolloids, 32, 42-51.

Yu, S. H., Hsieh, H. Y., Pang, J. C., Tang, D. W., Shih, C. M., Tsai, M. L., Tsai, Y. C., \& Mi, F. L. (2013). Active films from water-soluble chitosan/cellulose composites incorporating releasable caffeic acid for inhibition of lipid oxidation in fish oil emulsions. Food Hydrocolloids, 32, 9-19. 